\title{
AN AERIAL RADIOLOGICAL SURVEY OF THE FERNALD ENVIRONMENTAL MANAGEMENT PROJECT AND SURROUNDING AREA
}

\author{
FERNALD, OHIO
}

19980416044 


\section{DISCLAIMER}

This report was prepared as an account of work sponsored by an agency of the United States government. Neither the United States government nor an agency thereof, or any of their employees, makes a warranty, express or implied, or assumes legal liability or responsibility for the accuracy, completeness, or usefulness of any disclosed information, apparatus, product, or process, or represents that its use would not infringe privately owned rights. Reference herein to a specific commercial product, process, or service by trade name, trademark, manufacturer, or otherwise does not necessarily constitute or imply an endorsement, recommendation, or favoring by the United States government or an agency thereof. The views and opinions of the authors expressed herein do not necessarily state or reflect those of the United States government or an agency thereof.

This report has been reproduced directly from the best available copy.

This report is available to DOE and DOE contractors from the Office of Scientific and Technical Information, P.O. Box 62, Oak Ridge, TN 37831. Call (423) 576-8401 to obtain prices.

This report is available to the public from the National Technical information Service, U.S. Department of Commerce, 5285 Port Royal, Springfield, VA 22161. Call (703) 487-4650 for information. 


\title{
AN AERIAL RADIOLOGICAL SURVEY OF THE FERNALD ENVIRONMENTAL MANAGEMENT PROJECT AND SURROUNDING AREA
}

\author{
FERNALD, OHIO
}

DATE OF SURVEY: MAY 1994

K. A. Phoenix

Project Scientist

REVIEWED BY

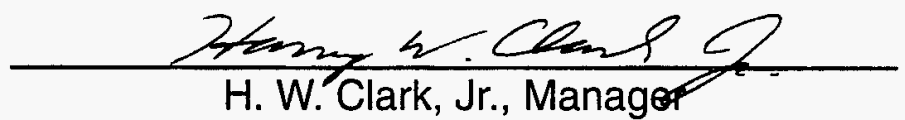

Radiation Science

This Document is UNCLASSIFIED

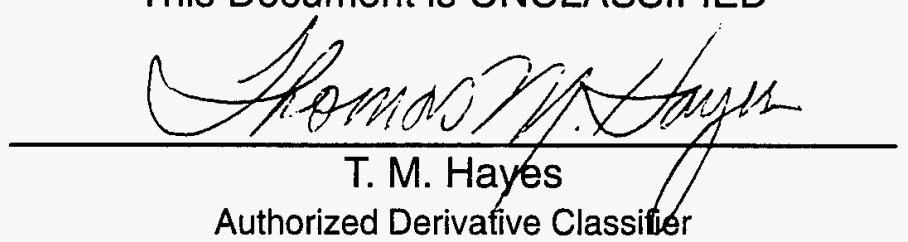

This work was performed for the U.S. Department of Energy by EG\&G/EM under Contract Number DE-AC08-93NV11265 and Bechtel Nevada under Contract Number DE-AC08-96NV11718. 


\begin{abstract}
An aerial radiological survey was conducted from May 17-22, 1994, over a 36-square-mile (93-square-kilometer) area centered on the Fernald Environmental Management Project located in Fernald, Ohio. The purpose of the survey was to detect anomalous gamma radiation in the environment surrounding the plant. The survey was conducted at a nominal altitude of 150 feet ( 46 meters) with a line spacing of 250 feet ( 76 meters). A contour map of the terrestrial gamma exposure rate extrapolated to 1 meter ( 3.3 feet) above ground was prepared and overlaid on an aerial photograph of the area. Analysis of the data for man-made sources showed five sites within the boundaries of the Fernald Environmental Management Project having elevated readings. The exposure rates outside the plant boundary were typical of naturally occurring background radiation. Soil samples and pressurized ion chamber measurements were obtained at four locations within the survey boundaries to supplement the aerial data.
\end{abstract}




\section{CONTENTS}

Abstract

\section{Sections}

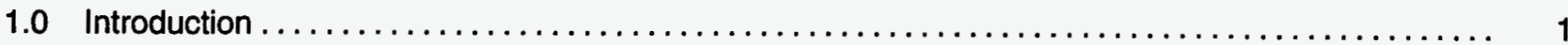

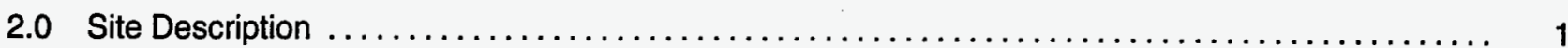

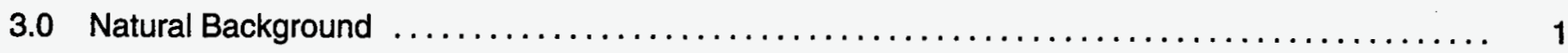

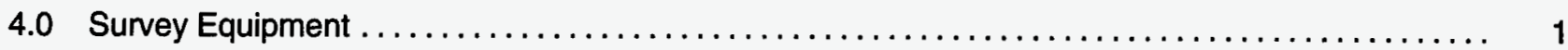

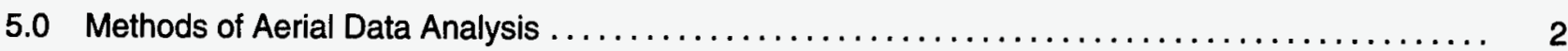

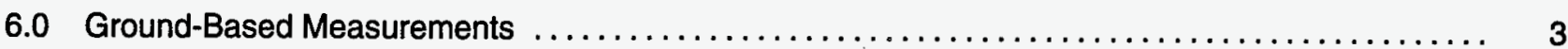

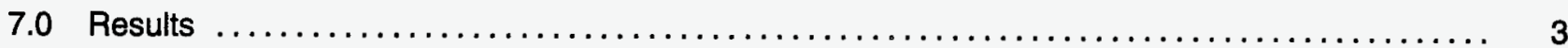

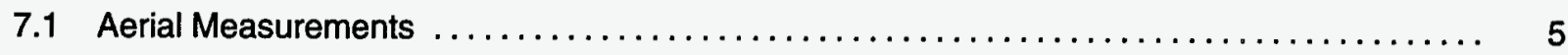

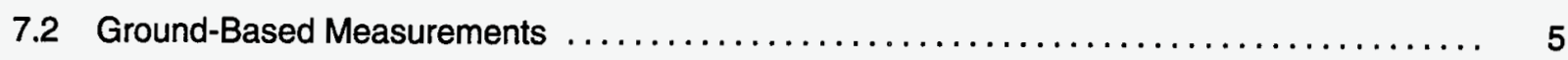

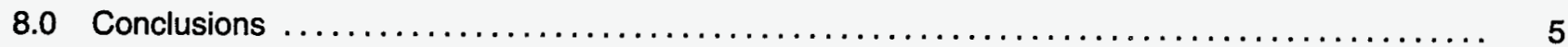

\section{Figures}

1 MBB BO-105 Helicopter with $\mathrm{Nal}(\mathrm{TI})$ Detector Pods Mounted above the Skids ............. 2

2 Isopleth Contour of the Fernald Environmental Management Project

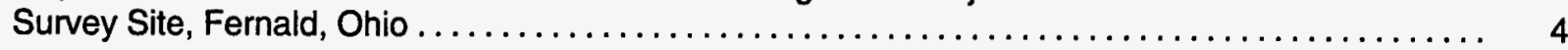

3 Gamma-Ray Energy Spectrum Showing Natural Terrestrial Background $\ldots \ldots \ldots \ldots \ldots \ldots \ldots$

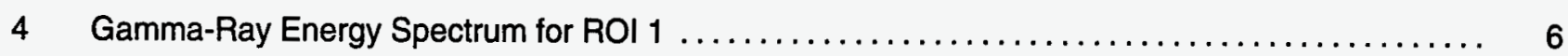

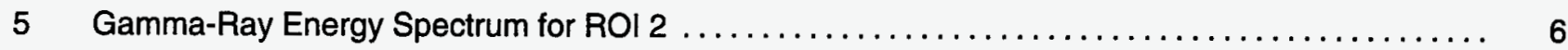

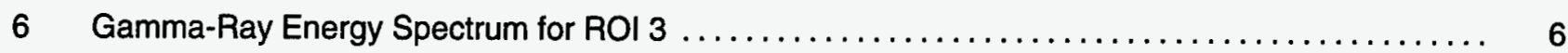

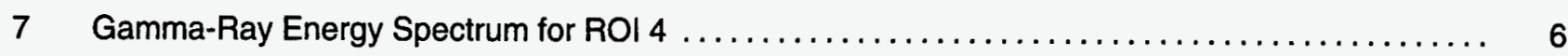

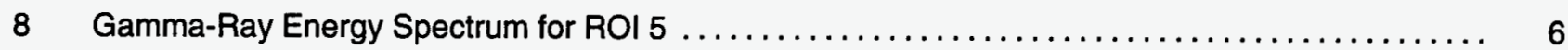

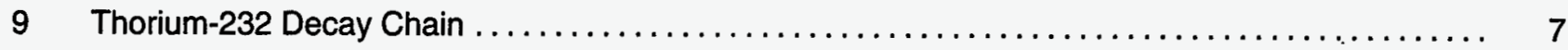

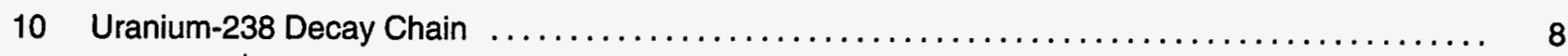

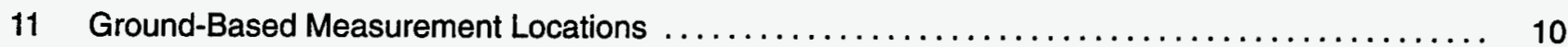




\section{Tables}

1 Comparison of Aerial and Ground-Based Measurements $\ldots \ldots \ldots \ldots \ldots \ldots \ldots \ldots \ldots \ldots \ldots . . \ldots$

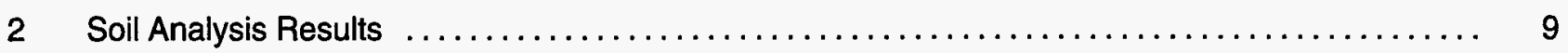

\section{Appendix}

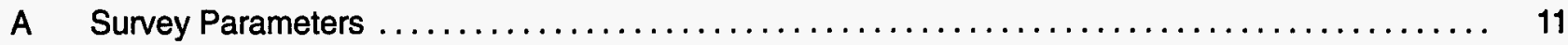

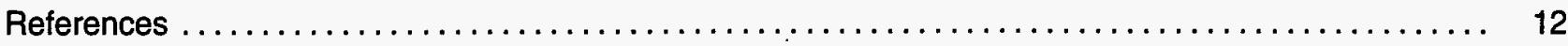




\subsection{Introduction}

An aerial radiological survey was performed over the Fernald Environmental Management Project (FEMP), located in Fernald, Ohio. The survey, conducted during the period of May 17-22, 1994, is typical of those repeated every several years around various facilities of interest to the U.S. Department of Energy (DOE). The surveys provide a means of monitoring changes in the gamma radiation levels at the facilities and in the surrounding areas. The FEMP survey was requested by DOE. Previous surveys of the plant, formerly called the Feed Materials Production Center, were performed in $1976^{1}$ and $1985 .{ }^{2}$

The aerial survey was performed by EG\&G Energy Measurements, Inc. (EG\&G/EM), which operated the Remote Sensing Laboratory (RSL) for the DOE Nevada Operations Office (DOE/NV). The RSL maintains and manages an aerial monitoring program called the Aerial Measuring System (AMS). Since its inception in 1958, the AMS has continued a nationwide effort to document baseline radiological conditions at nuclear-energy-related sites of interest to DOE. These sites include power plants, manufacturing and processing plants, and research laboratories that use nuclear materials.

\subsection{Site Description}

The FEMP, located in southwestern Ohio, processes uranium products for DOE. The survey area is characterized by occasional large hills and ridges. The Greater Miami River flows through the survey area on its way to the Ohio River. Significant nearby population centers include Ross, 1 mile (1.6 kilometers) to the northeast, and Cincinnati, 20 miles (32 kilometers) to the southeast.

The actual survey site consists of a $6-\times 6$-mile (9.7- $\times$ 9.7-kilometer) area centered on the plant. This area is only slightly larger than the $5-\times 5$-mile (8- $\times 8$-kilometer) area surveyed in 1985. A total of 127 parallel lines 250 feet ( 76 meters) apart were flown at an altitude of 150 feet (46 meters) and at an airspeed of 70 knots ( 36 meters per second).

\subsection{Natural Background}

Natural background radiation has three main sources: terrestrial radiation, cosmic radiation from space, and radon gas emanating from the ground. All three of these sources combine to contribute to the annual radiation dose to individuals.

The terrestrial component of natural background is due to gamma-ray-emitting radionuclides present in the soil. These naturally occurring radionuclides, members of the uranium $\left({ }^{238} \mathrm{U}\right)$ and thorium $\left({ }^{232} \mathrm{Th}\right)$ decay chains and a single isotope of potassium $\left({ }^{40} \mathrm{~K}\right)$, are long-lived radioactive materials with half-lives measured in billions of years. Gamma rays emitted from these radionuclides contribute to background radiation levels on the surface. Most often, regions exhibiting high levels of natural terrestrial radiation are located over particular geological deposits of materials high in the concentration of uranium and/or thorium or over sites where mining operations have produced tailings or other waste products. Terrestrial radiation levels can be significantly reduced due to shielding by moisture in the soil or overlying bodies of water or snow. The median whole-body dose-equivalent rate from terrestrial radiation for the United States is $\mathbf{3 0}$ millirems per year $(\mathrm{mrem} / \mathrm{yr}){ }^{3}$

Radon is produced through decay of radioactive materials in both the uranium and thorium chains. As a gas, radon migrates out of the ground into the air where it can contribute a dose to individuals on the surface. Because the mobility of the gas through rock fractures and soil is slowed by the presence of moisture, radon concentrations on the surface vary considerably.

Cosmic radiation arises from sources outside of the earth's atmosphere. The earth's atmosphere provides shielding equivalent to about 30 feet of water, so the radiation dose is significantly reduced by the time the cosmic radiation reaches the earth's surface. Consequently, cosmic radiation doses increase with elevation above sea level. The average whole-body dose equivalent in the United States from cosmic radiation is 3.2 microroentgens per hour $(\mu \mathrm{R} / \mathrm{h})(27 \mathrm{mrem} / \mathrm{yr}){ }^{4}$ However, in Denver, Colorado, with its elevation of 1 mile (1.6 kilometers), the dose equivalent from cosmic radiation is $6.0 \mu \mathrm{R} / \mathrm{h}(50 \mathrm{mrem} / \mathrm{yr})$.

\subsection{Survey Equipment}

The aerial measuring system used to perform the FEMP survey consisted of a radiation detector and data-acquisition computer system mounted aboard a high-performance helicopter. A data-analysis computer system located at the RSL facility at Andrews Air Force Base near Washington, D.C., supported the helicopter and allowed the spectral data to be reduced 
and presented as isopleth contour maps of exposure rates and isotopic intensities.

The Messerschmitt-Bolkow-Blohm (MBB) BO-105 helicopter, shown in Figure 1, was used as the aerial platform. The helicopter carried a crew of two and the Radiation and Environmental Data Acquisition and Recorder, Model IV, (REDAR IV) system. Two detector pods, each containing four 2- $\times 4-\times 16$-inch logtype, sodium iodide thallium-activated $[\mathrm{Nal}(\mathrm{T} l)]$ scintillation detectors, were mounted on the side landing skids of the helicopter. The signals from the eight detectors were combined and fed into a single analogto-digital converter (ADC) to record the gamma radiation. The output of a single detector was fed into a second ADC to extend the dynamic range and is useful in examining enhanced radiation areas.

The voltage pulses produced through the interaction of gamma rays with the $\mathrm{Nal}(\mathrm{T} l)$ crystals were analyzed by successive-approximation ADCs in the REDAR IV system. The REDAR IV is a multi-microprocessor data-acquisition and real-time analysis system designed to operate in the severe environments associated with platforms such as helicopters, fixed-wing aircraft, and various ground-based vehicles. The system displays radiation and positional information to the operator in real time through video displays and multiple light-emitting diode (LED) readouts. The gamma-ray spectrum, helicopter position, and weather data are recorded at one-second intervals on magnetic cartridge tapes for postflight analysis on a ground-based minicomputer system.

Helicopter position was established using two systems: a Real-Time Differential Global Positioning System (RDGPS) and a radar altimeter. The RDGPS is a ranging system which uses precise timing signals generated by a constellation of 24 satellites to determine position. The RDGPS stationary ground unit and

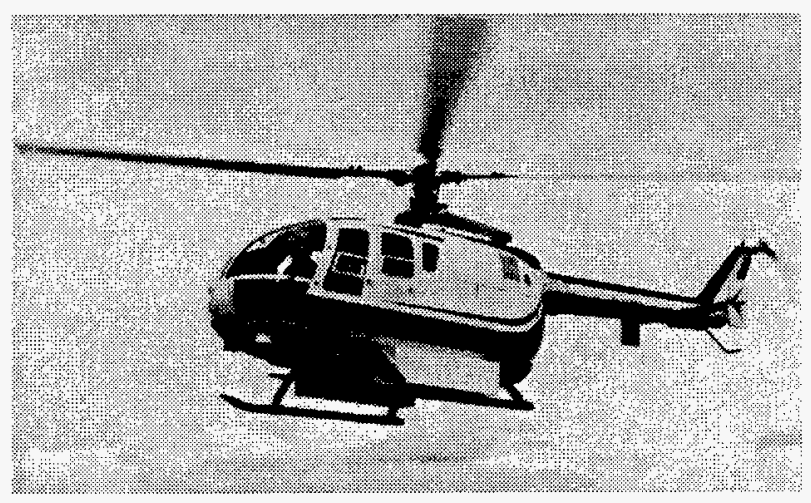

FIGURE 1. MBB BO-105 HELICOPTER WITH NaI(TT) DETECTOR PODS MOUNTED ABOVE THE SKIDS antenna were placed in or near the survey area. The accuracy of the Gobal Positioning System (GPS) is purposefully degraded by the Department of Defense. While in an operational mode called "Selective Availability" or S/A, a pseudo-random error is added to the satellite timing signals. $S / A$ is designed to deny hostile forces the precise positioning ability of the GPS. During a survey, the position of the ground station is continually determined and a correction term is transmitted to the aircraft's RDGPS unit, which then corrects its own position. This correction removes positional errors resulting from atmospheric conditions and S/A, greatly increasing the accuracy of the positional measurement. The RDGPS has the ability to locate the position of the aircraft to within \pm 16 feet (5 meters), as opposed to \pm 330 feet (100 meters) achieved with a standard GPS.

The radar altimeter determines the helicopter's altitude by measuring the round-trip propagation time of a signal reflected off the ground. For altitudes up to 1,000 feet ( 300 meters), the accuracy of this system is \pm 2 feet ( 0.6 meter) or \pm 2 percent, whichever is greater. The positional information from the RDGPS system was directed to an aircraft steering indicator used by the pilot to guide the aircraft along the predetermined flight lines.

In aerial surveys, aircraft altitude, line spacing, and speed are chosen to optimize the detector system's sensitivity to radionuclides and the system's spatial resolution while maintaining a safe flight configuration. For the FEMP survey, the helicopter flew 127 parallel lines, 250 feet ( 76 meters) apart, at an altitude of 150 feet (46 meters) and an airspeed of 70 knots (36 meters per second).

A minicomputer-based system, the Radiation and Environmental Data Analysis and Computer (REDAC) system, was used during the survey to evaluate the aerial data immediately following each survey flight. The REDAC system consists of a Data General 32-bit minicomputer system with two gigabytes of disk space for data storage, two 8-millimeter (1/4-inch) tape drives for data transfer and archiving, and a 36-inch color ink jet plotter for data contouring. Other peripheral devices include a laser printer and three graphics terminals with hard-copy units. This system has an extensive library of software routines available for complete data processing in the field.

\subsection{Methods of Aerial Data Analysis}

The algorithms described below were used to generate a terrestrial exposure-rate contour. ${ }^{5}$ To obtain this 
contour, the gross count data is first integrated between 38 and $3,026 \mathrm{keV}$ as follows:

$$
G C=\sum_{E=38 \mathrm{keV}}^{3026 \mathrm{keV}} S(E)
$$

$G C$ is the gross count rate, $E$ is the photon energy in $\mathrm{keV}$, and $S(E)$ is the gamma-ray energy spectrum (the number of counts collected in channels corresponding to energy $E$ ).

Because the contours are only meant to depict terrestrial radiation levels, background counts from cosmic radiation, airborne radon, and radiation from materials in the aircraft are subtracted. In addition, the terrestrial gross count rate is converted into an exposure rate at a 1-meter (3.3-foot) height by application of a conversion factor. The calculations for the exposure rate, $E R$, are summarized below. In addition, all counts were normalized using detector live time.

$$
E R=\frac{G C-B K G}{912} e^{\alpha A}
$$

In Equation 2, $B K G$ represents the background count rate from cosmic radiation, radon, and materials in the aircraft. The background count rate was determined by flying the aircraft over a body of water, shielding the aircraft from terrestrial sources of radiation so that only counts from cosmic radiation, radon, and the aircraft were observed. The particular body of water used during this survey was the Ohio River. The contours generated from these data reflect the total exposure rate at 1 meter ( 3.3 feet). A calculated cosmicray contribution of $3.7 \mu \mathrm{R} / \mathrm{h}$ was added to the reduced data before the contours were plotted. The typical and highly variable radon contribution of approximately $0.2 \mu \mathrm{R} / \mathrm{h}$ was not included in the contour.

The factor in the denominator of Equation 2 converts count rate to exposure rate and was determined from data obtained over the test line in Calvert County, Maryland. ${ }^{6}$ This factor has been adjusted for environmental differences such as temperature, humidity, and altitude between the Calvert County test line and the FEMP survey site. The exponential term in this equation corrects for changes in the attenuation of the gamma radiation in air due to slight variations in the aircraft's altitude, $A$. The attenuation coefficient, $\alpha=0.0021 \mathrm{ft}^{-1}$, was experimentally measured at the survey site.
The conversion from gross counts to exposure rate assumes the source is spread uniformly over the width of the detector footprint, or field of view, of approximately 300 feet (91 meters). Because the conversion assumes the source is spread evenly over the entire footprint, the exposure rate will be underestimated over sources that are small with respect to the size of the footprint. For example, an intense point source of radiation can produce counts equivalent to a much less intense large-area source.

Gross count data include contributions from natural sources of radiation. Consequently, these data will reflect variations in terrestrial radiation levels. Contours resulting from these variations in natural radiation levels will often match surface features, such as tree lines, boundaries of cultivated land, and bodies of water. Exposure-rate contours offer a sensitive means of identifying anomalous, potentially manmade changes in the radiation environment.

\subsection{Ground-Based Measurements}

To provide confirmation of the aerial measurements, a series of ground-based measurements was performed. At selected points within the survey site, exposure-rate measurements were made at a height of 1 meter (3.3 feet) using a Reuter-Stokes ionization chamber. In addition to the ion chamber measurements, the exposure rate at a height of 1 meter was inferred from two types of high-purity germanium, gamma spectroscopic measurements. The first consisted of gamma spectroscopic analysis of four soil samples from each of the selected locations. These samples were obtained to a depth of 15 centimeters (6 inches), dried, and counted at the EG\&G/EM Santa Barbara facility. The second consisted of in situ gamma spectroscopic analysis performed at each of the field locations. Exposure rates were then inferred from the concentrations of naturally occurring radionuclides determined by gamma spectroscopy. Detailed descriptions of the system and the procedures used for collecting and analyzing data from soil samples are outlined in separate publications. ${ }^{7,8}$

\subsection{Results}

The results of the aerial measurements are shown in Figure 2. An estimated cosmic-ray contribution of 3.7 $\mu \mathrm{R} / \mathrm{h}$ has been added to the terrestrial exposure rates at 1 meter. Five regions of interest (ROIs), corresponding to areas of maximum exposure rate, are also indicated on the map. $\mathrm{Net} \mathrm{Nal}(\mathrm{Tl})$ gamma-ray 


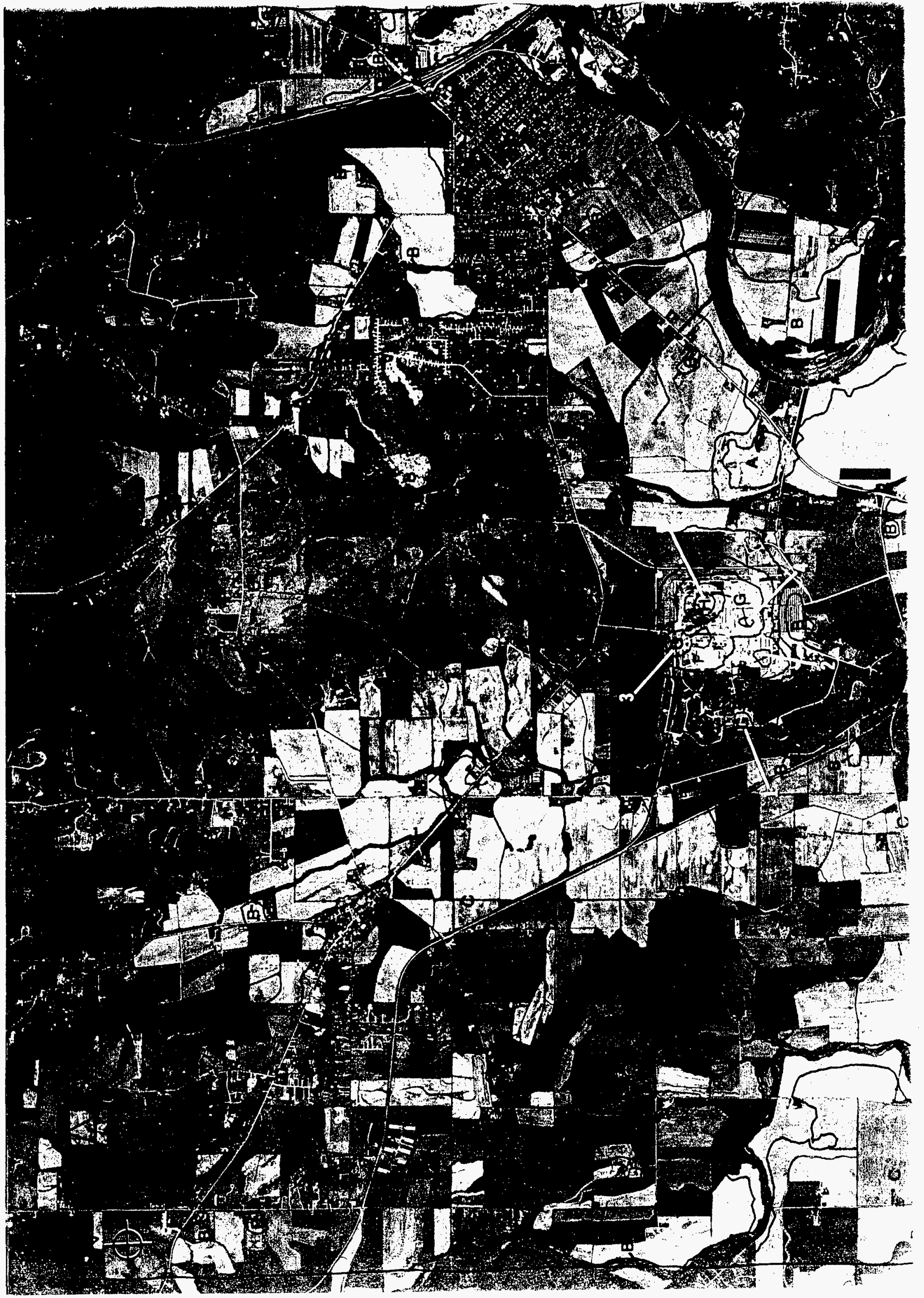




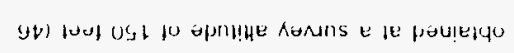

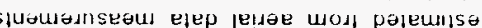

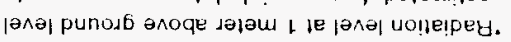

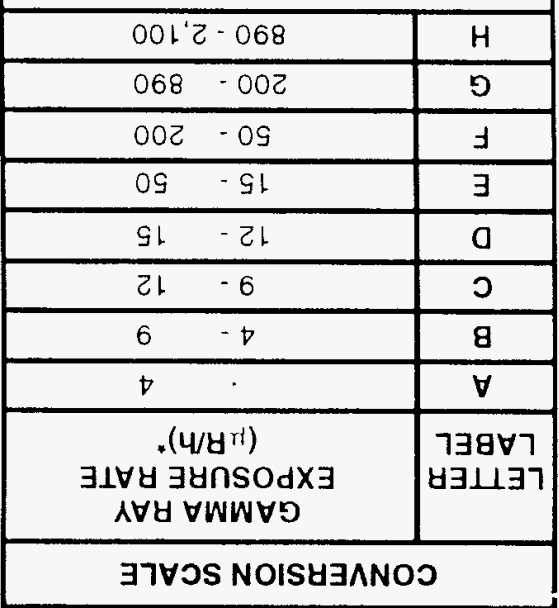
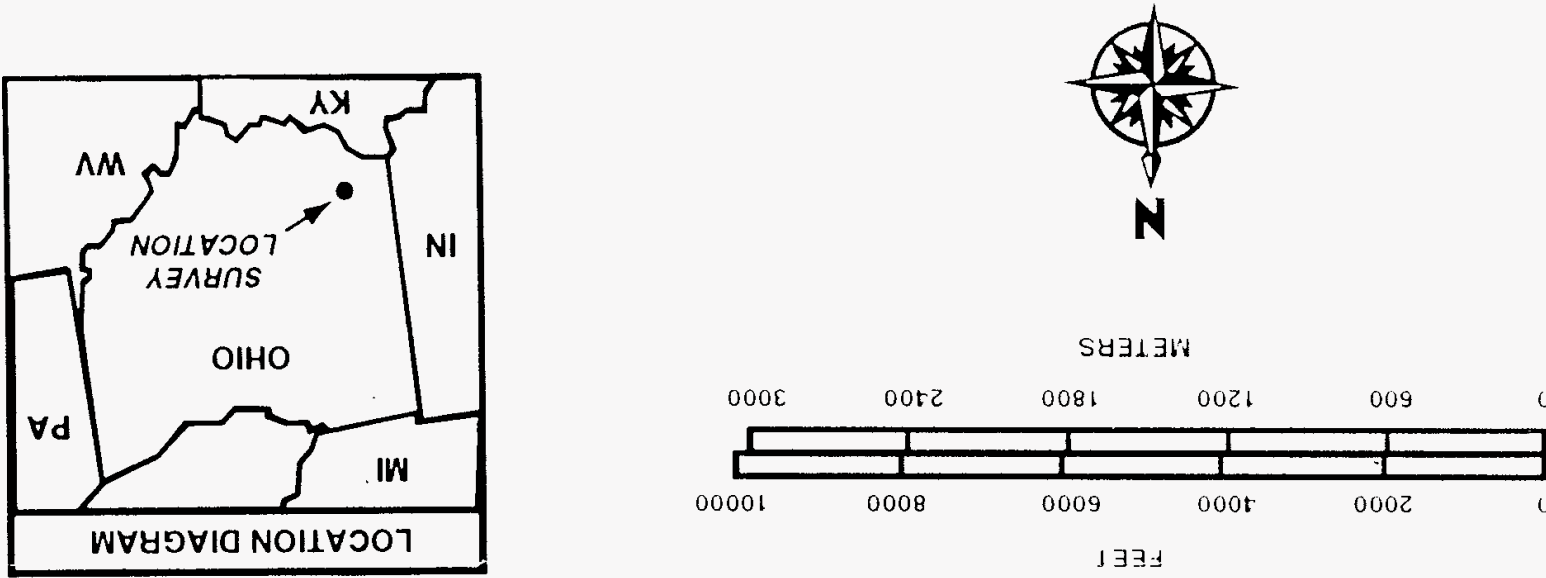

(ब)

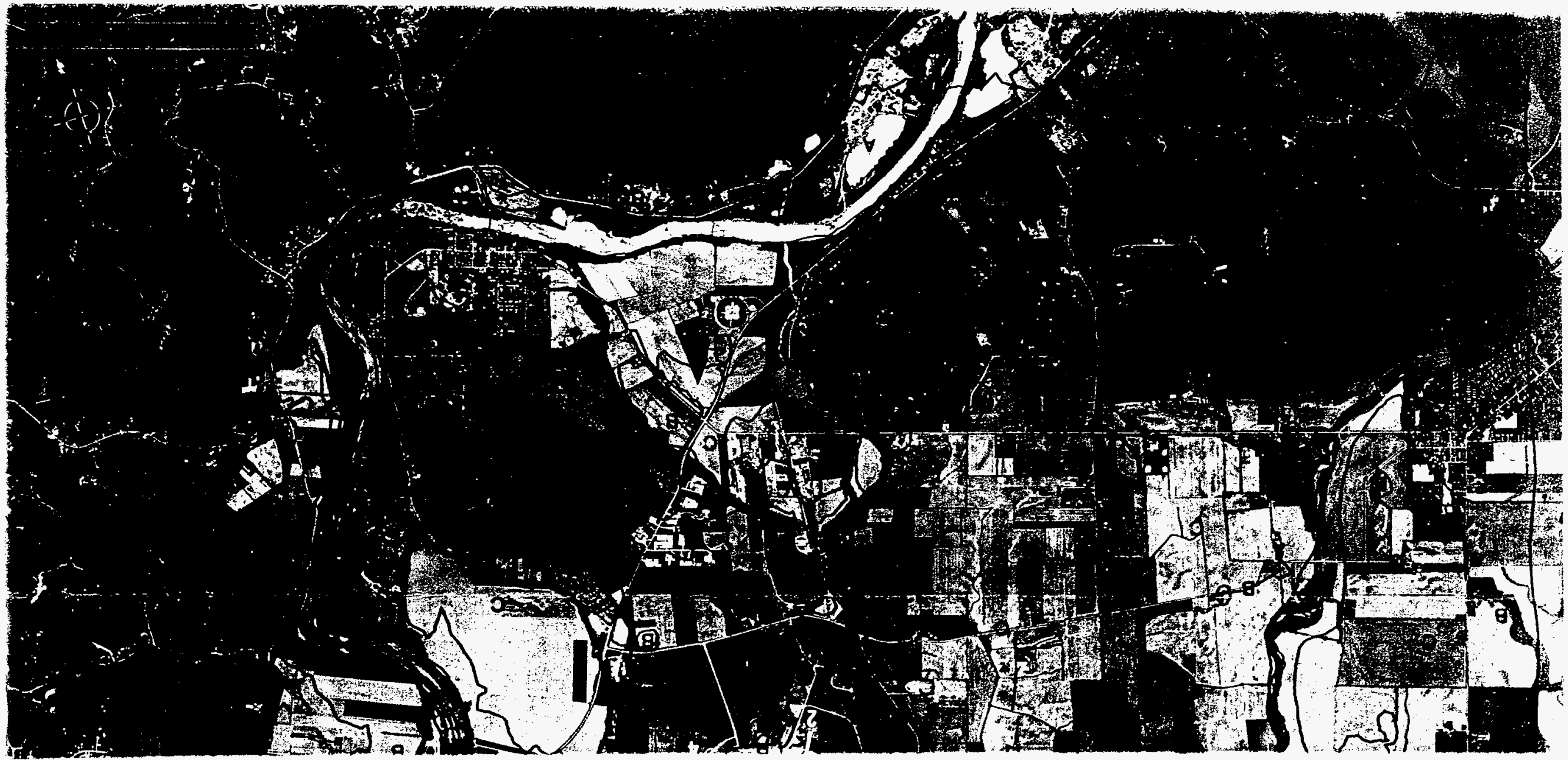



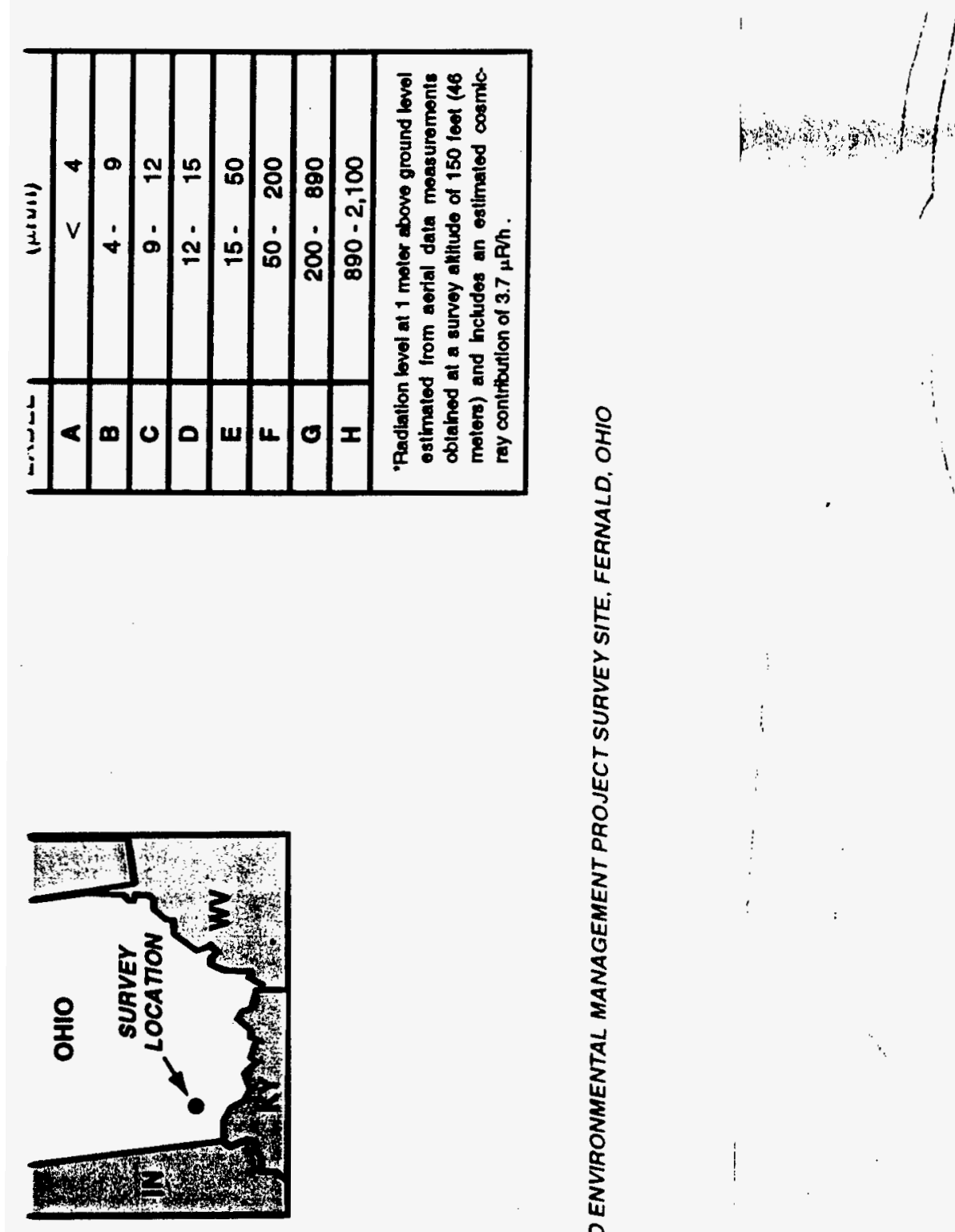

3

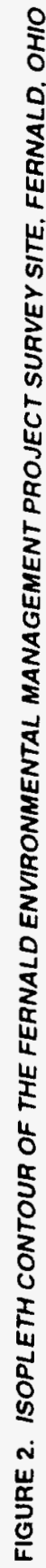


spectra from these regions were extracted for identification of the gamma-ray emitters. A typical background gamma-ray spectrum appears in Figure 3. Gamma-ray spectra for the five ROls appear in Figures 4 through 8.

\subsection{Aerial Measurements}

The survey area surrounding the FEMP consists of a fairly uniform background radiation field of 7 to $12 \mu \mathrm{R} / \mathrm{h}$. This level is typical throughout the United States. The outline of the Great Miami River is plainly visible where it passes though the survey area, as are the boundaries of several wooded areas. Many of the contours in this area roughly match those from the 1985 survey.

Figure 3 depicts a $\mathrm{Nal}(\mathrm{Tl})$ gamma-ray spectrum due to terrestrial background radiation. Counts for this spectrum were obtained within the survey boundary, over a large area surrounding the FEMP. A major peak occurs at an energy of $1,460 \mathrm{keV}$. The source of this radiation is the naturally occurring isotope of potassium $\left({ }^{40} \mathrm{~K}\right)$. Also visible in this spectrum are peaks due to gamma rays from actinium-228 $\left({ }^{228} \mathrm{Ac}\right)$ at $911 \mathrm{keV}$ and thallium-208 $\left({ }^{208} \mathrm{TI}\right)$ at $2,614 \mathrm{keV}$. Both of these radionuclides are members of the ${ }^{232}$ Th chain of naturally occurring radionuclides (see Figure 9 on page 7). Bismuth-214 (214 $\mathrm{Bi}$ ), a member of the ${ }^{238 \mathrm{U}}$ chain of naturally occurring radionuclides, contributes peaks at 1,120, 1,728, and 2,204 keV (see Figure 10 on page 8 ).

The FEMP itself is the only area where exposure rates were significantly above background levels. The large-area averaging inherent in the aerial measurement system has resulted in an underestimate of the peak exposure rates in these areas. The actual exposure rates could be as much as two orders of magnitude larger than shown in Figure 2, depending on how localized the radiation source is. Also, the contours will often appear to imply a large-area source of radiation near high-exposure-rate areas when, in fact, the source is quite localized. This is caused by radiation from the high-exposure-rate area traveling some distance before striking the detectors on the aircraft at an oblique angle. Five ROls, labeled in Figure 2, were chosen to correspond to the peak exposure rates measured over the plant. Figures 4 through 8 are gamma-ray spectra obtained with the airborne system over these regions.

The ${ }^{214} \mathrm{Bi}$ peaks appearing in Figure 4 are seen wherever radium-226 ( $\left.{ }^{226} \mathrm{Ra}\right)$, radon-222 (222Rn), or ${ }^{238 \mathrm{U}}$ and its progeny are present. The magnitude of the exposure rates encountered in ROI 1 suggests that a large quantity of such material is present at this location.

The gamma-ray spectra obtained over ROls 2,3 , and 4 appear in Figures 5, 6, and 7, respectively. Gammaray spectra such as these are typical of $238 U$ but only when uranium has been separated from its progeny, particularly ${ }^{214} \mathrm{Bi}$. Before separation, the $1,001-\mathrm{keV}$ and $765-\mathrm{keV}$ peaks from protactinium- $234 \mathrm{~m}\left({ }^{234 \mathrm{mPa}}\right)$ are overwhelmed by ${ }^{214} \mathrm{Bi}$ emissions. Also present in Figures 5 and 6 is a ${ }^{208} \mathrm{Tl}$ peak at $2,614 \mathrm{keV}$.

The gamma-ray spectrum obtained over ROI 5 contains prominent ${ }^{208} \mathrm{Tl}$ and ${ }^{228} \mathrm{Ac}$ peaks. The $\mathrm{Nal}(\mathrm{Tl})$ detectors used are not able to resolve the $911-\mathrm{keV}$ and $969-\mathrm{keV}{ }^{228} \mathrm{Ac}$ peaks. Instead, a distorted peak appears in this energy region. Both ${ }^{208} \mathrm{Tl}$ and ${ }^{228} \mathrm{AC}$ are members of the naturally occurring ${ }^{232} \mathrm{Th}$ decay chain.

\subsection{Ground-Based Measurements}

The results of the ionization chamber exposure-rate measurements, as well as the results from the soil sampling, are tabulated in Tables 1 and 2 . The three ground-based ionization chamber measurements falling within the survey site boundary are in agreement with the levels plotted in Figure 2. All three fall within the 9 to $12 \mu \mathrm{R} / \mathrm{h}$ contour. The fourth measurement, at Site 15 , is located outside the survey site boundary. The soil sample locations are shown in Figure 11.

The activities from the soil analysis fall within the wide range of values typically encountered within surface soils in the United States. Where the ground-based measurements from the 1985 survey have been repeated, the recent results show agreement with the 1985 results within their stated limits of precision.

\subsection{Conclusions}

Contours within the FEMP area are similar to those measured in 1985. Although the radionuclides identified in the high-exposure-rate areas are naturally occurring, the levels encountered are greatly enhanced due to industrial activities at the plant. There are no areas of man-made or enhanced naturally occurring radioactivity outside the plant boundary. 


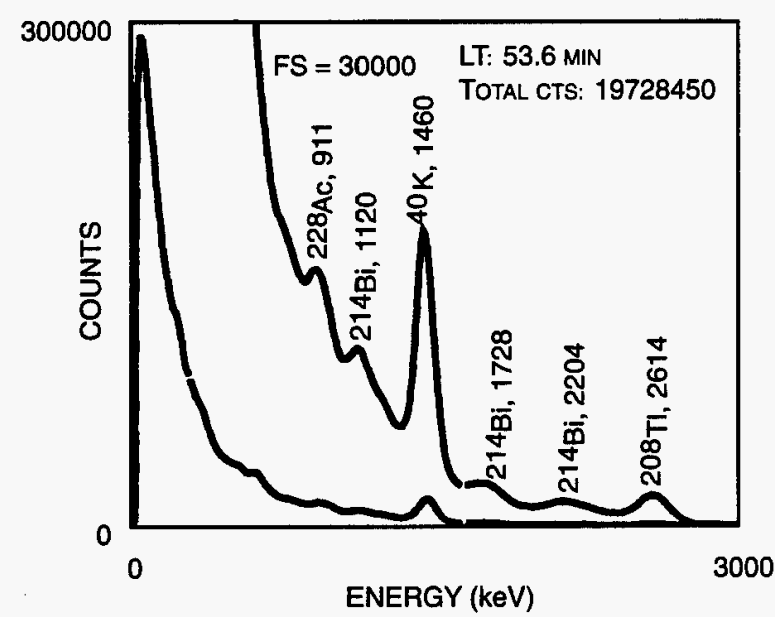

FIGURE 3. GAMMA-RAY ENERGY SPECTRUM SHOWING NATURAL TERRESTRIAL BACKGROUND

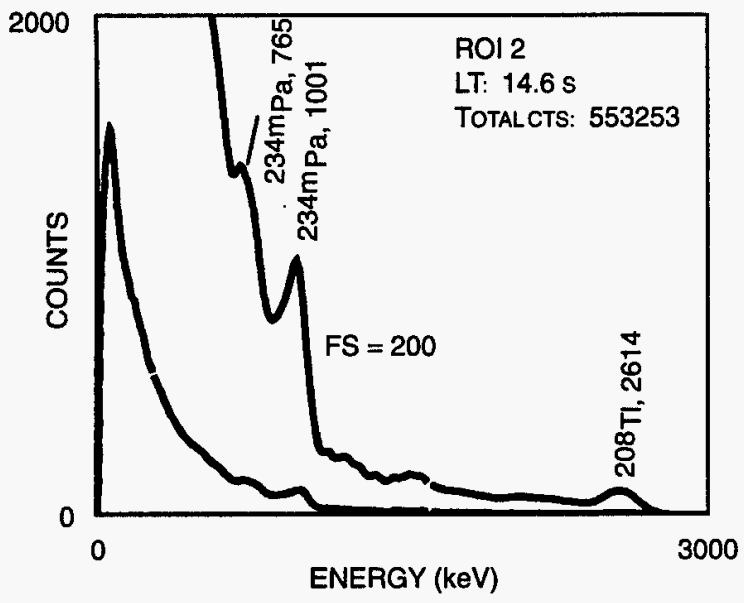

FIGURE 5. GAMMA-RAY ENERGY SPECTRUM FOR ROI 2

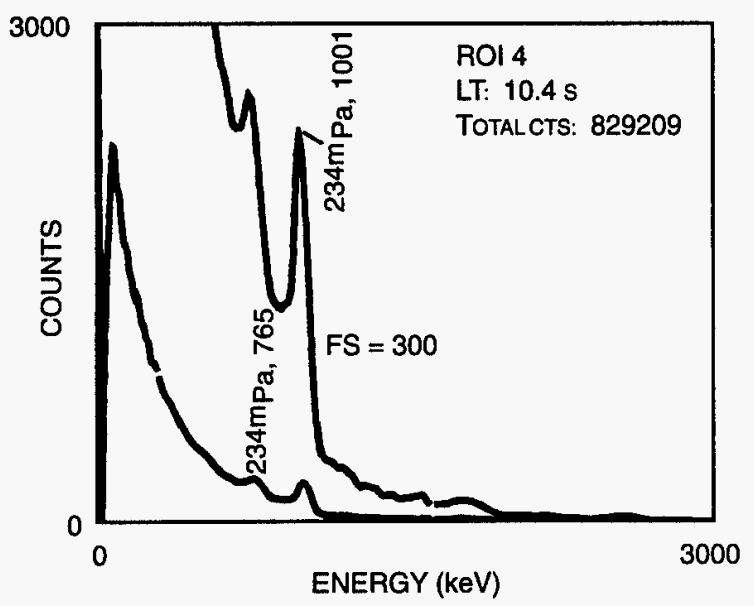

FIGURE 7. GAMMA-RAY ENERGY SPECTRUM FOR ROI 4

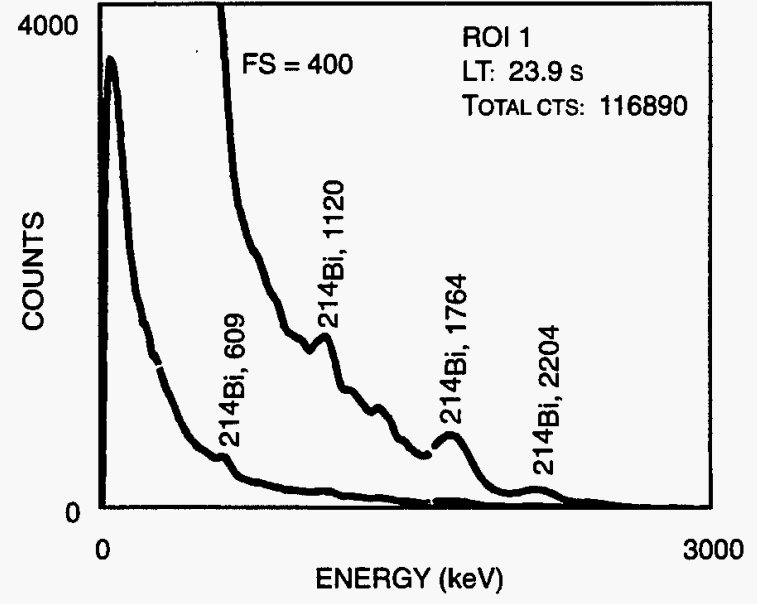

FIGURE 4. GAMMA-RAY ENERGY SPECTRUM FOR ROI 1

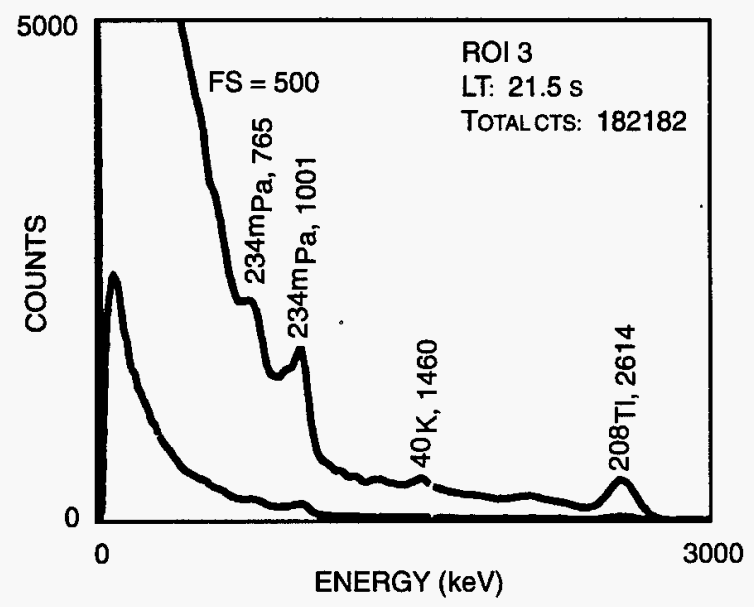

FIGURE 6. GAMMA-RAY ENERGY SPECTRUM FOR ROI 3

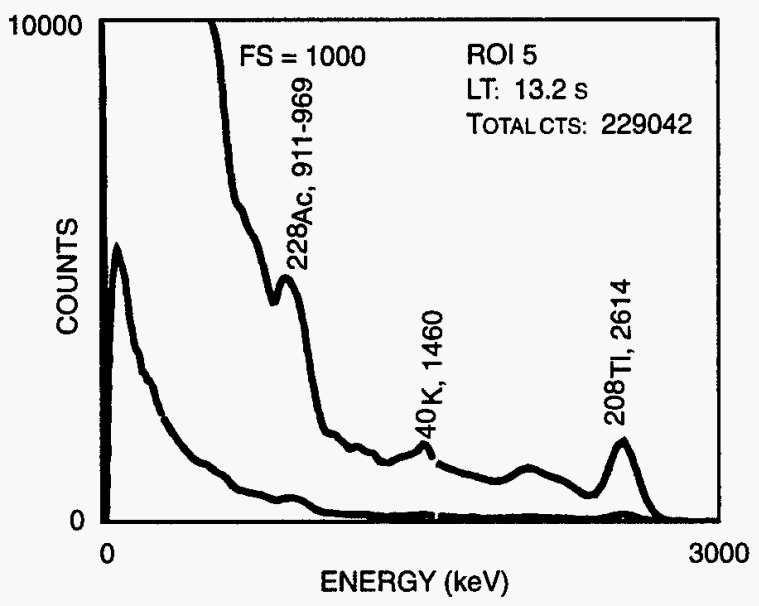

FIGURE 8. GAMMA-RAY ENERGY SPECTRUM FOR ROI 5 


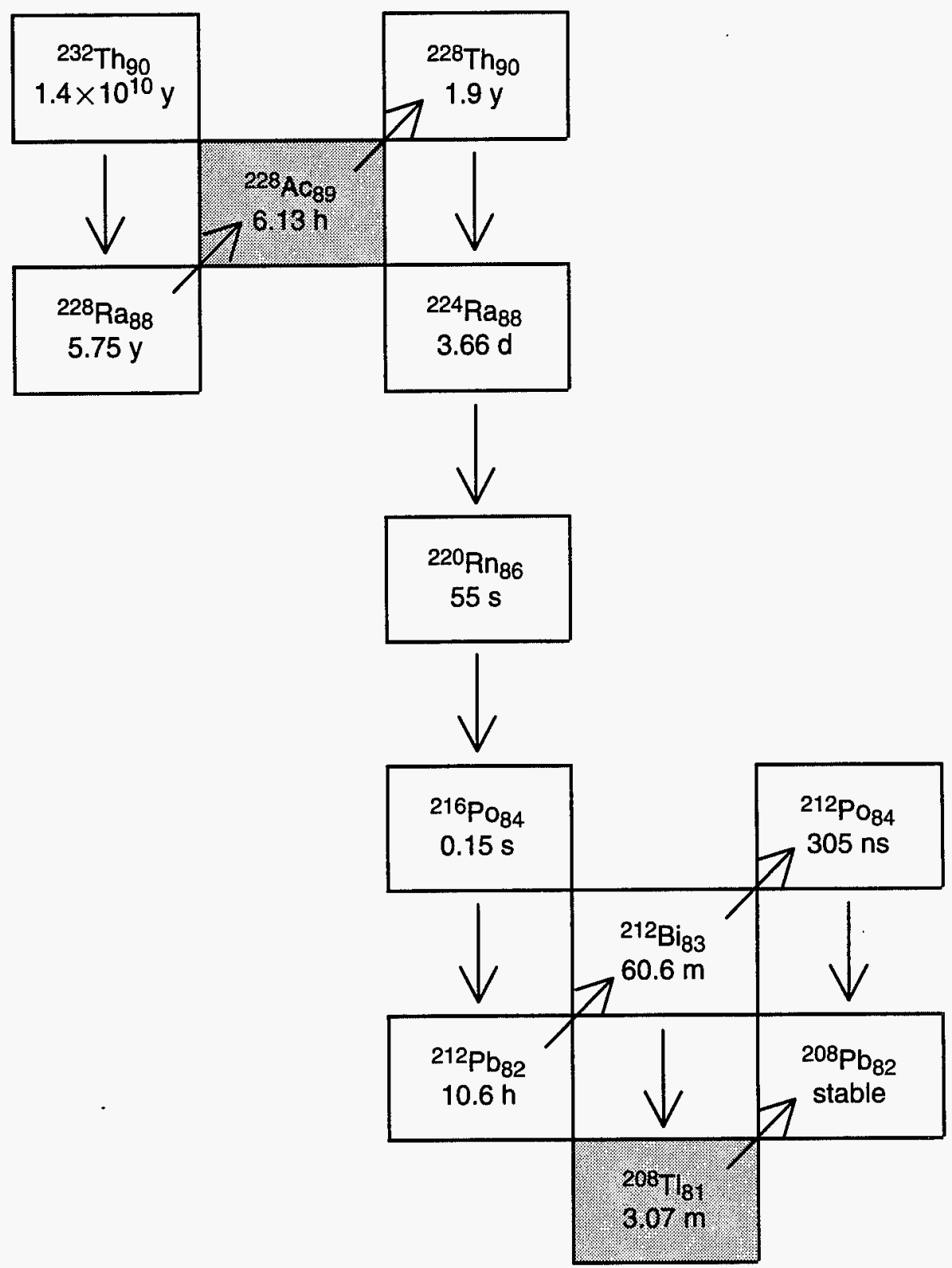

FIGURE 9. THORIUM-232 DECAY CHAIN. Beta decays are denoted by diagonal arrows; alpha decays are indicated by vertical arrows. Gamma rays from shaded isotopes are used in the analysis. 


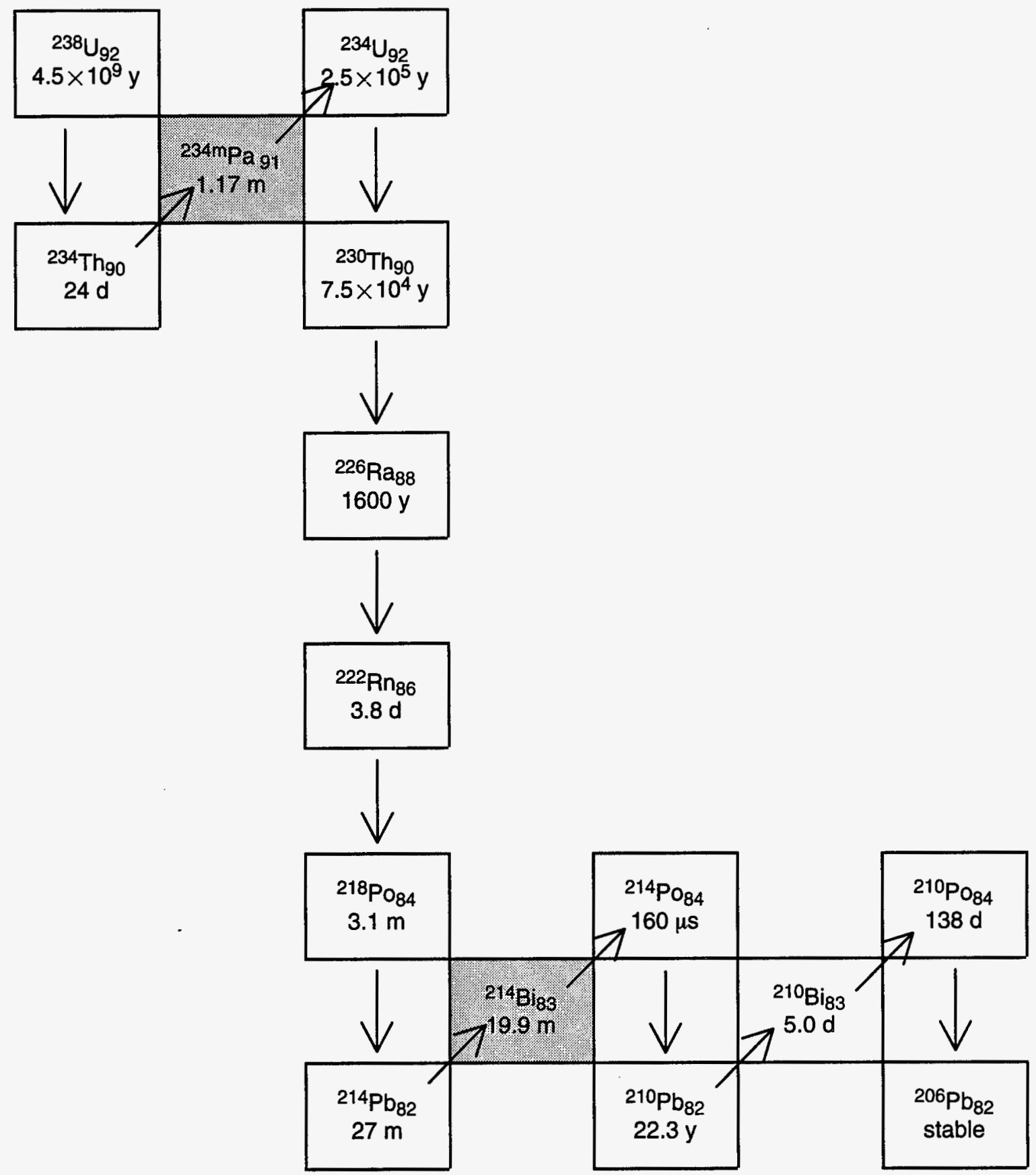

FIGURE 10. URANIUM-238 DECAY CHAIN. Beta decays are denoted by diagonal arrows; alpha decays are indicated by vertical arrows. Gamma rays from shaded isotopes are used in the analysis. 
Table 1. Comparison of Aerial and Ground-Based Measurements

\begin{tabular}{c|c|c|c}
\hline \multirow{2}{*}{$\begin{array}{c}\text { Site ID } \\
\text { Number }\end{array}$} & $\begin{array}{c}\mid c \\
\text { Soil Analysis } \\
\text { Estimate }\end{array}$ & $\begin{array}{c}\text { Exposure Rate } \\
(\mu \mathrm{R} / \mathrm{h} \text { at 1 m AGL })\end{array}$ \\
\cline { 2 - 4 } & $9.7 \pm 0.7$ & lon Chamber b & Inferred Aerial Data ${ }^{\mathrm{a}}$ \\
\hline $1 \mathrm{~A}$ & $10.2 \pm 1.0$ & $8.7 \pm 0.5$ & $9.7 \pm 0.5$ \\
2 & $11.7 \pm 0.3$ & $9.3 \pm 0.5$ & $9.6 \pm 0.7$ \\
14 & $11.2 \pm 0.3$ & $9.6 \pm 0.5$ & $9.2 \pm 0.3$ \\
15 & $10.0 \pm 0.8$ & \\
\hline
\end{tabular}

a Estimate includes a cosmic-ray contribution of $3.7 \mu R / \mathrm{h}$ and a moisture correction of the form $1 /(1+\mathrm{m})$ where $m$ is the fractional moisture content.

b Reuter-Stokes PIC Model RSS-112, Serial Number G-003

Table 2. Soil Analysis Results

\begin{tabular}{|c|c|c|c|c|c|c|}
\hline \multirow{2}{*}{$\begin{array}{c}\text { Site ID } \\
\text { Numbera }\end{array}$} & \multirow{2}{*}{$\begin{array}{c}\text { Moisture } \\
(\%)\end{array}$} & \multicolumn{5}{|c|}{ Average Isotopic Concentration \pm Standard Deviation $(\mathrm{pCi} / \mathrm{g})$} \\
\hline & & $234 \mathrm{mPa}$ & ${ }^{226} \mathbf{R a}$ & 232Th & ${ }^{137}$ Cs & ${ }^{40} \mathrm{~K}$ \\
\hline $1 A^{b}$ & $19 \pm 1$ & $N^{C}$ & $1.0 \pm 0.2$ & $0.9 \pm 0.06$ & $0.35 \pm 0.07$ & $14.9 \pm 0.4$ \\
\hline 2 & $18 \pm 4$ & ND & $1.0 \pm 0.1$ & $0.9 \pm 0.1$ & $0.27 \pm 0.08$ & $17 \pm 1$ \\
\hline 3 & $13 \pm 1$ & $4 \pm 1$ & $1.0 \pm 0.1$ & $1.1 \pm 0.1$ & $0.28 \pm 0.01$ & $18.4 \pm 0.3$ \\
\hline 5 & $11 \pm 2$ & ND & $1.0 \pm 0.1$ & $1.0 \pm 0.1$ & $0.24 \pm 0.02$ & $19 \pm 1$ \\
\hline $6 \mathrm{~A}$ & $4 \pm 1$ & ND & $0.50 \pm 0.05$ & $0.20 \pm 0.02$ & ND & $5.9 \pm 0.1$ \\
\hline 7 & $8 \pm 1$ & ND & $0.40 \pm 0.05$ & $0.50 \pm 0.05$ & ND & $11.3 \pm 0.2$ \\
\hline 8 & $12 \pm 2$ & $2 \pm 1$ & $0.7 \pm 0.1$ & $0.8 \pm 0.1$ & $0.08 \pm 0.01$ & $15.1 \pm 0.1$ \\
\hline 9 & $10 \pm 1$ & ND & $0.8 \pm 0.1$ & $1.0 \pm 0.1$ & $0.24 \pm 0.01$ & $17.1 \pm 0.3$ \\
\hline 11 & $16 \pm 1$ & $3 \pm 1$ & $0.9 \pm 0.03$ & $1.0 \pm 0.02$ & $0.35 \pm 0.01$ & $15.0 \pm 0.8$ \\
\hline 12 & $17 \pm 2$ & $3 \pm 1$ & $0.8 \pm 0.1$ & $1.0 \pm 0.1$ & $0.35 \pm 0.01$ & $15.1 \pm 0.3$ \\
\hline 13 & $20 \pm 2$ & $3 \pm 1$ & $1.1 \pm 0.1$ & $1.3 \pm 0.1$ & $0.37 \pm 0.01$ & $20.8 \pm 0.3$ \\
\hline 14 & $14 \pm 1$ & $3 \pm 1$ & $1.1 \pm 0.03$ & $1.1 \pm 0.02$ & $0.26 \pm 0.01$ & $21.6 \pm 0.8$ \\
\hline 15 & $15 \pm 3$ & ND & $1.0 \pm 0.1$ & $1.2 \pm 0.04$ & $0.18 \pm 0.16$ & $18.4 \pm 1.5$ \\
\hline
\end{tabular}

a Site inaccessible. Alternate Site $1 \mathrm{~A}$ used.

${ }^{b}$ Remedial/clean-up actions prevented entrance to Sites 4, 6B, and 10.

c ND indicates that the isotope was not detected in the measured soil sample. 


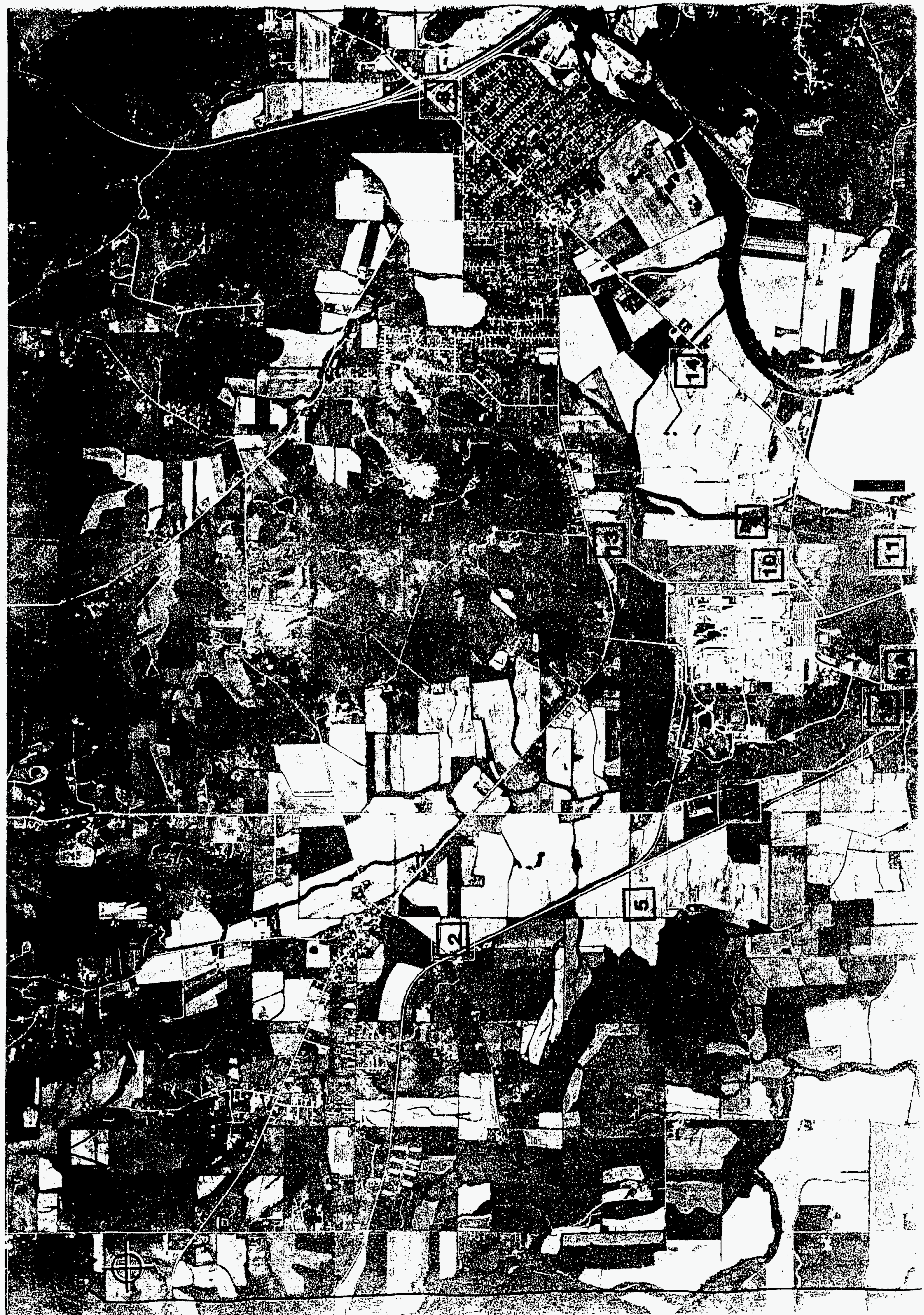




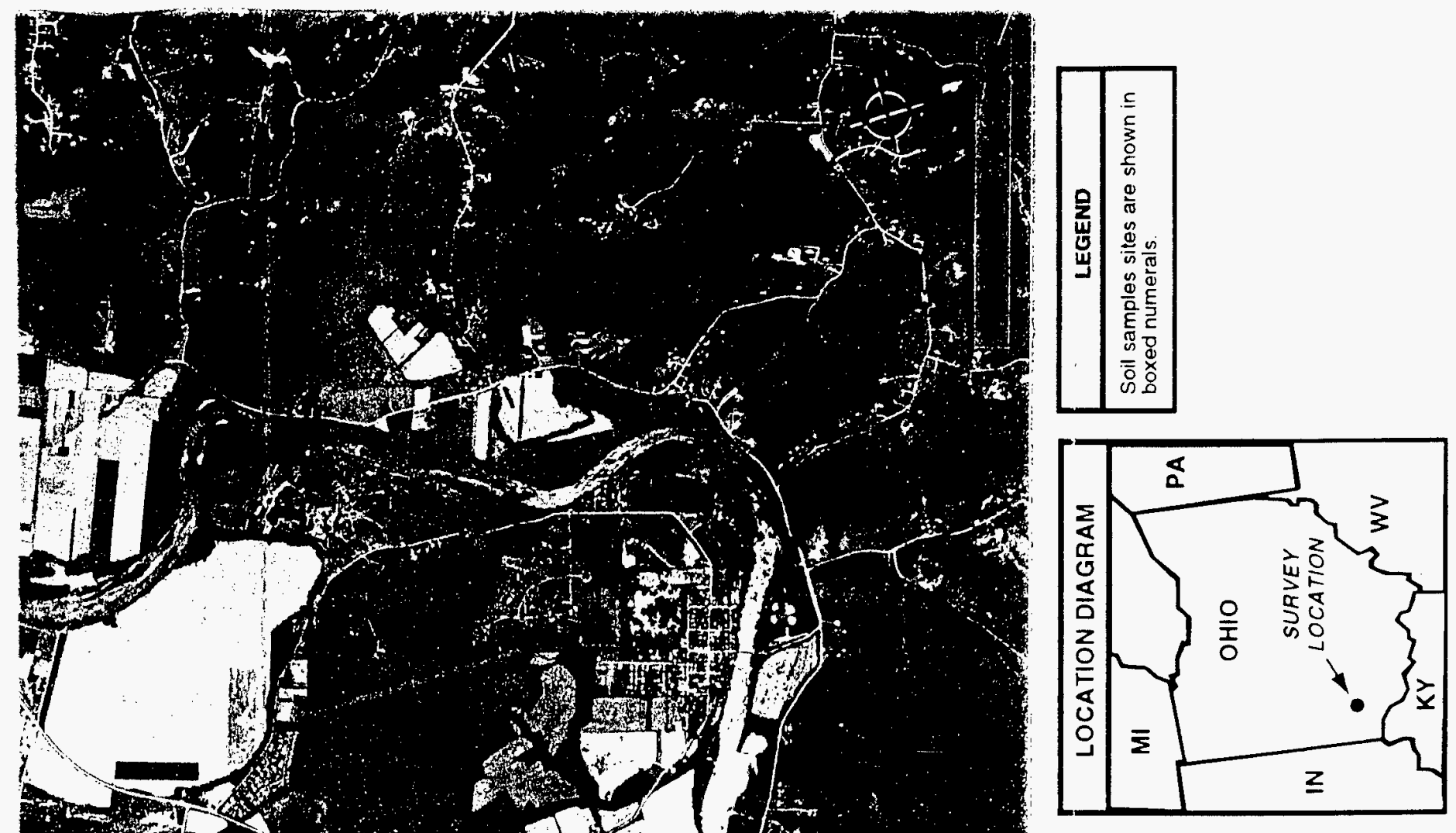



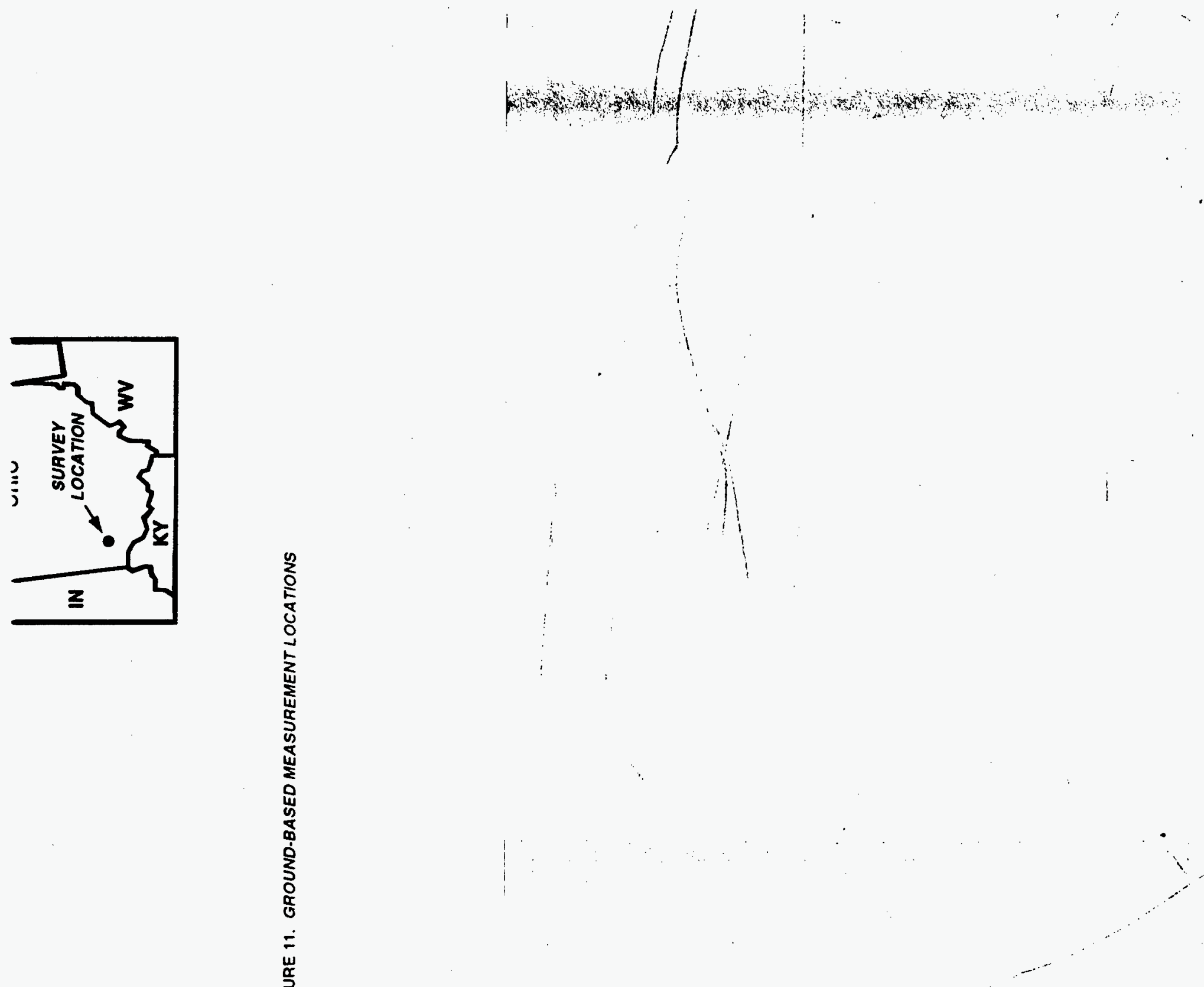

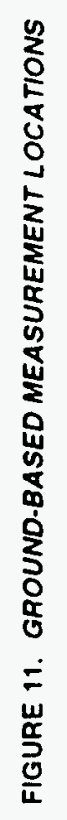

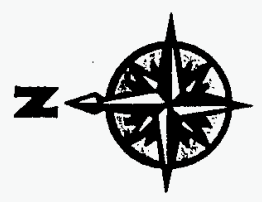




\section{APPENDIX A}

\section{SURVEY PARAMETERS}

Survey Site:

Fernald Environmental Management Project

Survey Location:

Fernald, Ohio

Survey Area:

$6 \times 6$ miles $(9.7 \times 9.7$ kilometers $)$

Survey Date:

May 17-22, 1994

Survey Altitude:

150 feet (46 meters)

Survey Speed:

70 knots ( 36 meters per second)

Line Spacing:

250 feet (76 meters)

Line Direction:

North-South

Number of Lines:

127

Detector Array:

Eight 2- $\times 4-\times 16$-inch $\mathrm{Nal}(\mathrm{T} l)$ detectors

Two 2- $\times 4-\times 4$-inch $\mathrm{Nal}(\mathrm{Tl})$ detectors

Data Acquisition System: REDAR IV

Aircraft:

MBB BO-105 Helicopter (Tail Number: N40EG)

Project Scientist:

K. Phoenix

Survey Scientist:

G. Sampoll-Ramirez

Data Processing:

Gross Count Energy Window: $38-3,026 \mathrm{keV}$

Conversion Factors: $912 \mathrm{cps} /(\mu \mathrm{R} / \mathrm{h})$

Cosmic Contribution: $3.7 \mu \mathrm{R} / \mathrm{h}$ 


\section{REFERENCES}

1. Feimster, E.L. An Aerial Radiological Survey of the Area Surrounding the Feed Materials Production Center. Report No. EGG-1183-1680, 1979; EG\&G, Las Vegas, NV.

2. Shipman, G.R. An Aerial Radiological Survey of the Feed Materials Production Center and Surrounding Area. Report No. EGG-10282-1084, 1985; EG\&G/EM, Las Vegas, NV.

3. Exposure of the Population of the United States and Canada from Natural Background Radiation. NCRP Report No. 94, 1987; National Council on Radiation Protection and Measurements, Bethesda, MD.

4. Klement, Jr., A.W.; C.R. Miller; R.P. Minx; and B. Shleien. Estimates of Ionizing Radiation Doses in the United States, 1960-2000. U.S. EPA Report ORP/CSD72-1, 1972; EPA, Washington, D.C.

5. Boyns, P.K. The Aerial Radiological Measuring System (ARMS): Systems, Procedures and Sensitivity (1976). Report No. EGG-1183-1691, 1976; EG\&G, Las Vegas, NV.

6. Mohr, R.A. Ground Truth Measurements at the Calvert County, Maryland Test Line. Report No. EGG-10282-2066, 1985; EG\&G/EM, Santa Barbara, CA.

7. Quam, W. and K. Engberg. Low Background Ge(Li) Detector with Anticoincidence NaI Annulus, (2nd Revision). Report No. EGG-1183-2326 (Revised), 1978; EG\&G, Santa Barbara, CA.

8. Mohr, R.A.; A.E. Fritzsche; and L.A. Franks. Ground Survey Procedures. Report No. EGG-1183-2339, 1976; EG\&G, Santa Barbara, CA. 
DOE/DP

L. E. Gordon-Hagerty

DOE/NV

K. D. Lachman

Public Reading Room TIRC

DOE/FN

J. A. Jalovec
(1)

(1)

(1)

(1)

(15)

(1)
BN

$\begin{array}{ll}\text { C. E. Ezra } & \text { LVAO } \\ \text { P. P. Guss } & \text { WAMO } \\ \text { R. E. Kelley } & \text { LVAO } \\ \text { K. R. Lamison } & \text { LVAO } \\ \text { J. T. Mitchell } & \text { LVAO } \\ \text { K. A. Phoenix } & \text { WAMO } \\ \text { L.G. Sasso } & \text { LVAO }\end{array}$

(1)

\section{LIBRARIES}

RSL

WAMO

FERMCO

P. Kraps
(2)

AN AERIAL RADIOLOGICAL SURVEY OF THE FERNALD ENVIRONMENTAL MANAGEMENT PROJECT AND SURROUNDING AREA FERNALD, OHIO DOE/NV/11718-019 DATE OF SURVEY: MAY 1994 DATE OF REPORT: APRIL 1997 


\section{M97054116 \\ ||||||||||||||||||||||||||||||||||||||||||}

Report Number (14) DOE/NV/117/8--019

Publ. Date (11)

$$
199704
$$

Sponsor Code (18) DOE/DP,XF

UC Category (19) $4 \mathrm{C}-702$ DOE/ER 